\title{
The Work Product Doctrine: Functional Considerations and the Question of the Insurer's Claim File
}

\author{
Mary Beth Brookshire Young $\dagger$
}

When a party opposes an insurer in litigation, access to the claim file is often a critical issue. The claim file is the best and most obvious record of both the underlying facts and the insurer's handling of the claim. The extent to which it is discoverable may determine whether the case goes forward and which party ultimately prevails. Because the claim file is so valuable, insurers vigorously seek to protect it from discovery. Their most effective shield is the work product doctrine.

The doctrine's primary purpose generally has been to encourage optimal amounts of trial preparation by guaranteeing parties that their pretrial efforts need not be shared with the opposition except under limited circumstances. Federal and most state rules of civil procedure shield materials prepared "in anticipation of litigation," but allow the party seeking discovery to access such materials by demonstrating a "substantial need" for the materials and an inability to obtain their equivalent elsewhere without "undue hardship."

Not surprisingly, the boundaries of work product protection are not always clear. The insurance context provides unique difficulties in this regard. Because of the nature of the insurance business, much of what an insurer does is arguably trial preparation. Insurers point out that the possibility of litigation is ever present, and, therefore, that every claim investigation anticipates litigation to some extent. This position has a certain common sense appeal. Common sense also suggests, however, that if the purpose of work product protection is to encourage pretrial preparation, there is no reason to protect preparation that would be done even if not protected. In many cases, much of the claim file will fall into this category. Thus, insurance discovery disputes force courts to consider how to treat materials that are ar-

$\dagger$ B.S. 1990, University of Kentucky; M.S. 1993, Georgia Institute of Technology; J.D. Candidate 1998, The University of Chicago.

1 FRCP 26(b)(3). 
guably prepared in anticipation of litigation, but are used for other purposes as well.

If a court determines that a document has been prepared in "anticipation of litigation," the court may then have to consider whether the "substantial need" exception applies. Courts disagree over whether an insured's allegation that his insurer has denied or otherwise evaluated his claim in bad faith establishes substantial need for an otherwise protected file. A liberal discovery rule may encourage frivolous allegations of bad faith, while restricting discovery may make it difficult to prove bad faith, leaving insurers unaccountable.

How courts treat work product questions in insurance cases affects the nature of cases brought, which parties prevail, and the kind of investigations insurers conduct. Despite the important interests at stake, courts have failed to reach a consensus on how to interpret the work product doctrine in the insurance context. This Comment will examine, in the context of first party insurance, ${ }^{2}$ how to interpret the doctrine so that trial preparation materials are adequately protected at a minimum cost to society.

Part I summarizes the history and purposes of the work product doctrine and discusses Federal Rule of Civil Procedure 26(b)(3). Part II introduces the issues involved in applying the doctrine in insurance cases and the approaches courts have taken to those issues. Part III examines how and when work product protection affects the amount of trial preparation and discusses four costs to society that may result from a court's interpretation of the work product doctrine: divergence costs, missed sharing costs, administrative costs, and side-effects costs. Part IV uses these costs to evaluate the approaches courts have taken in insurance cases, emphasizing the interdependence between the "anticipation of litigation" requirement and allegations of bad faith. This Part concludes that for first party insurance cases, the best approach presumes that portions of the claim file prepared prior to the insurer's decision to deny a claim are not in anticipation of litigation, and does not allow an allegation of bad faith to satisfy the substantial need exception automatically.

2 "First party" insurance provides for the payment of benefits to the insured upon the occurrence of specified events. Examples include life insurance, health insurance, and disability insurance. "Third party" insurance typically indemnifies the insured against liability to third parties. See Robert E. Keeton and Alan I. Widiss, Insurance Law: A Guide to Fundamental Principles, Legal Doctrines and Commercial Practices $\$ 4.10(a)$ (West 1988). 


\section{THE WORK PRODUCT DOCTRINE AND RULE 26(b)(3)}

\section{A. Hickman and Rule 26(b)(3)}

Modern analyses of work product issues generally focus on Federal Rule of Civil Procedure 26(b)(3) or its state counterparts, but the doctrine antedates these procedural rules. The Supreme Court first definitively analyzed the justifications for and limits of the work product doctrine in Hickman $v$ Taylor, ${ }^{3}$ where the Court denied a party's request for discovery of witness statements taken by opposing counsel. According to the Court, the request was "an attempt, without purported necessity or justification, to secure written statements, private memoranda and personal recollections prepared or formed by an adverse party's counsel in the course of his legal duties." The Court reasoned that such an attempt contradicted the "public policy underlying the orderly prosecution and defense of legal claims." Yet, even while embracing protection of trial preparation, the Hickman court foresaw limits to the doctrine, noting that "[w]here relevant and non-privileged facts remain hidden in an attorney's file and where production of those facts is essential to the preparation of one's case, discovery may be properly had." The Court left further development of the boundaries of the doctrine to the lower courts.

Between the 1947 Hickman decision and 1970, courts sought to flesh out the protection afforded by the work product doctrine. Conflicts arose on a number of issues, including the applicability of work product protection to preparation by nonattorneys and the showing of need required to overcome work product protection. ${ }^{7}$ In 1970 , the work product doctrine was incorporated into the Federal Rules of Civil Procedure, in part to resolve these conflicts. ${ }^{8}$ The current Rule 26(b)(3) provides that:

[A] party may obtain discovery of documents and tangible things otherwise discoverable ... and prepared in anticipation of litigation or for trial by or for another party or by or

\footnotetext{
${ }^{3} 329$ US 495 (1947).

- Id at 510.

5 Id.

Id at 511.

7 See generally 4 James Wm. Moore, et al, Moore's Federal Practice II 26.14 at 285-91 (Matthew Bender 2d ed 1996).

" Prior to the 1970 amendments, the federal rules required "good cause" for the discovery of any document. The 1970 amendments removed this general "good cause" requirement, and at the same time provided for special protection for "documents and other tangible things" that were prepared in anticipation of litigation. See Notes of Advisory Committee on 1970 Amendments to FRCP 26(b).
} 
for that other party's representative (including the other party's attorney, consultant, surety, indemnitor, insurer, or agent) only upon a showing that the party seeking discovery has substantial need of the materials in the preparation of the party's case and that the party is unable without undue hardship to obtain the substantial equivalent of the materials by other means. ${ }^{9}$

Most states now have work product provisions that are identical, or extremely similar, to the federal rule. ${ }^{10}$

Two features of the federal rule are worth noting. First, the rule protects only "documents and tangible things." Even if a document is itself protected, an opposing party may still discover the underlying facts through depositions or other discovery techniques. ${ }^{12}$ Second, to merit protection, a document must have been prepared in "anticipation of litigation." If the document meets the anticipation of litigation standard, the party seeking discovery may access the document only by demonstrating a "substantial need" for the document and "undue hardship"13 in obtaining its substantial equivalent by other means. ${ }^{14}$

FRCP 26(b)(3).

${ }^{10}$ Thirty-four states have provisions identical to $26(\mathrm{~b})(3)$, ten have provisions almost identical to $26(\mathrm{~b})(3)$, while six states have provisions that differ materially from the federal rule. See Elizabeth Thornburg, Rethinking Work Product, $77 \mathrm{Va}$ L Rev 1515, 1520-21 \& nn 29-31 (1991) (surveying state discovery rules). In diversity cases, the federal work product doctrine rather than the state rule applies. See Moore, et al, 4 Moore's Federal Practice II 26.15[5] at 326-27 (cited in note 7).

${ }^{11}$ Nontangible items, while unprotected by $26(b)(3)$, may still be protected as work product by Hickman and subsequent case law. See, for example, Clute $v$ Davenport Co, 118 FRD 312, 315 (D Conn 1988) ("Both Hickman v. Taylor and subsequent cases make clear that the [work product] doctrine is not limited in its scope to discovery of documents and other tangible items...." ).

${ }^{12}$ See Notes of Advisory Committee on 1970 Amendments to FRCP 26(b) (cited in note 8); Ring $v$ Commercial Union Insurance Co, 159 FRD 653, 657 (M D NC 1995).

${ }^{13}$ While "substantial need" and "undue hardship" are purportedly distinct, the practical difference between them is slight.

"Rule 26(b)(3) extends special protection to "opinion work product," providing that "[i]n ordering discovery of such materials when the required showing has been made the court shall protect against disclosure of the mental impressions, conclusions, opinions, or legal theories of an attorney or other representative of a party concerning the litigation." Some courts have interpreted this rule to establish an absolute privilege for opinion work product. See Duplan Corp v Moulinage et Retorderie de Chavanoz, 509 F2d 730, 734 (4th Cir 1974) (" $[N]$ o showing of relevance, substantial need or undue hardship should justify compelled disclosure of an attorney's mental impressions, conclusions, opinions, or legal theories."). Other courts allow the discovery of opinion work product in limited instances. For example, many courts will allow discovery of opinion work product if it is "directly at issue." See Reavis v Metropolitan Property and Liability Insurance Co, 117 FRD 160, 164 (S D Cal 1987) (explaining that while Rule 26(b)(3) affords mental impressions "greater protection" than non-opinion work product, mental impressions are not immune from discovery). The Supreme Court has held that the usual showing of substantial need and undue hardship is not sufficient to obtain access to opinion work product, but has not de- 


\section{B. Justifications for the Doctrine}

Meaningful application of the work product doctrine to insurance cases requires an understanding of the purposes of the doctrine itself. Four main justifications of the doctrine have been articulated. First, the doctrine prevents attorneys from hesitating to do trial preparation. ${ }^{15}$ Second, work product protection may deter attorneys from altering their preparation to avoid having a written record of information. ${ }^{16}$ Third, allowing discovery of work product could have a "demoralizing effect on the legal profession."17 Finally, allowing discovery of work product could lead to a party's attorney being called as a witness. ${ }^{18}$

\section{RULE 26(b)(3) AND THE PROBLEM Of INSURANCE ClatM FIIES}

Parties attempt to gain access to an insurer's claim file in a variety of situations. Cases may center on disputes about coverage or on disputes about whether contractual responsibilities have been carried out in good faith. Because the file will gener-

cided whether the protection is absolute. Upjohn Co $v$ United States, 449 US 383, 401 (1981).

${ }^{15}$ Hesitance to do preparation may be motivated by three factors: the lessened value of preparation if it must be shared, the fear that in completely developing one's case one might uncover potentially adverse information that the opponent is unlikely to uncover on his own, and the possibility of obtaining the information passively by discovering it from the other party. See D. Christopher Wells, The Attorney Work Product Doctrine and Carry-Over Immunity: An Assessment of Their Justifications, 47 U Pitt L Rev 675, 684-85 (1986). Compare Thornburg, $77 \mathrm{Va} \mathrm{L}$ Rev at 1527 (cited in note 10) (arguing that both the "bad facts" and "lazy lawyer" rationales are unpersuasive).

${ }^{16}$ Hickman, 329 US at 511 ("Were such materials open to opposing counsel on mere demand, much of what is now put down in writing would remain unwritten."). Modern commentators do not give much weight to this justification, however. For example, Judge Easterbrook argues that it may be unrealistic in light of the complexity of modern litigation to think that attorneys will "stop taking notes." See Frank H. Easterbrook, Insider Trading, Secret Agents, Evidentiary Privileges, and the Production of Information, $1981 \mathrm{~S}$ Ct Rev 309, 362 (arguing that parties are likely to accommodate their behavior to the disclosure rules in only a limited manner).

${ }^{17}$ Hickman, 329 US at 511 ("An attorney's thoughts, heretofore inviolate, would not be his own. Inefficiency, unfairness, and sharp practices would inevitably develop in the giving of legal advice and the preparation of cases for trial. The effect on the legal profession would be demoralizing."). This justification has fallen out of vogue today. Thornburg argues that concern for the morale and reputation of the legal profession is not compelling, and even offers some lawyer jokes as support for her position. Thornburg, $77 \mathrm{Va} L$ Rev at $1539-40$ \& $n 119$ (cited in note 10 ).

${ }^{18}$ See Hickman, 329 US at 517 (Jackson concurring) (explaining that if an attorney were forced to deliver to the opposition an account of what a witness told him prior to trial, that account would inevitably diverge at least slightly from the witness's at-trial testimony. Then, the door would be open to the adversary to call the attorney to the stand to "impeach" the witness). Compare Model Rules of Professional Conduct Rule 3.7 ("A lawyer shall not act as advocate at a trial in which the lawyer is likely to be a necessary witness."). 
ally contain information about a claim that is the subject of the litigation, it will often satisfy the basic relevance requirement for discoverability. ${ }^{19}$

This threshold inquiry of relevance is not dispositive, however. In response to a plaintiff's discovery request, insurers frequently seek to shield portions of the claim file from discovery by invoking the work product doctrine. Courts therefore must decide which parts of the claim file are protected by Rule 26(b)(3) or its state counterparts. This Part discusses the issues courts encounter in deciding which portions of the claim file to protect, and introduces the approaches courts have taken to those issues.

\section{A. The "Anticipation of Litigation" Requirement}

In seeking to determine which portions of a claim file are protected, courts must first evaluate which parts of the file meet the "anticipation of litigation" threshold. The cases exhibit at least five general approaches.

First, a number of courts have limited the reach of the work product doctrine by holding that materials prepared in the ordinary course of business will not be considered to have been prepared in anticipation of litigation ("ordinary course of business exception"). ${ }^{20}$ For example, the court in Atlanta Coca-Cola Bottling Co $v$ Transamerica Insurance $C^{21}$ refused to protect much of the claim file because "the evaluation of claims of its policyholders is the regular, ordinary, and principal business" of an insurer. $^{22}$

\footnotetext{
19 "Parties may obtain discovery regarding any matter, not privileged, which is relevant to the subject matter involved in the pending action. ..." FRCP 26(b)(1). In some cases, a party may attempt to obtain discovery of files regarding claims other than the one that is the subject of the litigation. See generally Thomas E. Workman, Plaintiffs Right to the Claim File, Other Claim Files and Related Information: The Ticket to the Gold Mine, 24 Tort and Ins L J 137 (1988) (arguing that discovery of other claim files "will be the battleground of the future" and is likely to be resolved in favor of discoverability).

$\infty$ The ordinary course of business exception is not limited to the insurance context. See Notes of Advisory Committee on the 1970 Amendments to FRCP 26(b) (cited in note 8); Binks Manufacturing Co $v$ National Presto Industries, Inc, 709 F2d 1109, 1120 (7th Cir 1983) (party's in-house memorandum prepared in the ordinary course of business discoverable in a contract dispute).

${ }^{21} 61$ FRD 115 (N D Ga 1972).

${ }^{22}$ Id at 118. See also Baker $v$ CNA Insurance Co, 123 FRD 322, 328 (D Mont 1988) (explaining that "where the contested material is prepared with the primary motive of assisting in a party's day to day business, the material is not protected trial preparation even if there exists a likelihood of ultimate litigation"); Western Natl Bank v Employers Insurance of Wausau, $105 \mathrm{FRD} 55,57$ (D Colo 1985) (noting that insurers' "factual investigations of claims" are within the ordinary course of business exception).
} 
A second line of cases has interpreted the anticipation of litigation requirement much more broadly, protecting even routine investigations by insurers ("broad protection approach"). ${ }^{23}$ These courts reason that the rule requires only that the document be prepared in anticipation of litigation, regardless of whether that is its sole or even primary motivation. Accordingly, the broad protection approach rejects the ordinary course of business exception: even if a document was prepared in the ordinary course of business, it will be granted protection as long as one reason for its preparation was anticipation of litigation. ${ }^{24}$

Third, some courts have narrowly construed the anticipation of litigation requirement to hold that only the portions of the claim file prepared at the direction of counsel are protected ("direction of counsel rule"). This approach effectively maintains the distinction between materials prepared in anticipation of litigation and those prepared in the ordinary course of business, but employs the use of counsel to draw the line between the two. In the leading case of Thomas Organ Co v Jadranska Slobodna Plovidba ${ }^{25}$ the court held that reports that do not involve legal expertise are conclusively presumed to be in the ordinary course of business. ${ }^{26}$

A fourth group of decisions employs a "denial presumption." According to this presumption, any investigation undertaken before a claim is denied is not in anticipation of litigation, while any investigation undertaken after denial is in anticipation of litigation. ${ }^{27} \mathrm{~A}$ party seeking discovery may overcome the denial presumption by an appropriate showing; the exact showing required varies among courts. In Pete Rinaldi's Fast Foods, Inc $v$

${ }^{23}$ See, for example, Almaguer $v$ Chicago, Rock Island \& Pacific Railroad Co, 55 FRD 147, 149 (D Neb 1972) (Statements obtained by defendant's claim agent as part of a routine accident investigation and in anticipation of a possible claim are protected by the work product doctrine.); Ashmead v Harris, 336 NW2d 197, 200 (Iowa 1983) (Materials prepared by an insurance company in a routine accident investigation are protected by the work product doctrine.).

24 See Almaguer, 55 FRD at 149.

${ }^{25} 54$ FRD 367 (N D IIl 1972).

${ }^{25}$ Id at 372 ("[A]ny report or statement made by or to a party's agent . . . which has not been requested by nor prepared for an attorney nor which otherwise reflects the employment of an attorney's legal expertise must be conclusively presumed to have been made in the ordinary course of business."). See also Westhemco Ltd $v$ New Hampshire Insurance Co, 82 FRD 702, 708 (S D NY 1979), modified on other grounds, Commercial Union Insurance Co $v$ Albert Pipe \& Supply Co, 484 F Supp 1153, 1154 (S D NY 1980).

${ }^{27}$ Technically, the turning point is the time at which the insurer reaches a decision on a claim, whether or not that decision is a "denial." Naturally, litigated cases generally involve at least a partial denial, such as a decision by the insurer to pay a smaller amount than the insured believes he is owed. See Moore, et al, 4 Moore's Federal Practice II 26.14 at 294-99 (cited in note 7). 
Great American Insurance Companies, ${ }^{28}$ the court held that to overcome the presumption and win protection for documents prepared prior to the denial of the claim, the insurer must present "specific evidentiary proof of objective facts demonstrating a resolve to litigate" prior to denial. ${ }^{29}$ In Harper $v$ Auto-Owners Insurance $\mathrm{Co}^{30}$ the court made the presumption even more difficult to overcome by requiring proof that "at the time of the preparation there was a reasonable anticipation of litigation and that the document was prepared solely for litigation."

Finally, many courts decline to fashion any kind of rule specific to the discoverability of claim files. Instead, they rely on a general understanding of what "anticipation of litigation" means and start from scratch with each new insurance case to determine how the facts accord with that understanding ("ad hoc approach"). These courts examine the facts of each case to determine "whether in light of the factual context the document can fairly be said to have been prepared or obtained because of the prospect of litigation." ${ }^{\text {"31 }}$ Some courts indicate that the real issue is whether litigation was the "primary motivating purpose" behind the creation of a document. ${ }^{32}$ Other courts focus on when the prospect of litigation became "substantial" or "identifiable,"33 which depends on the nature of the claim and investigation.

${ }^{23} 123$ FRD 198 (M D NC 1988).

${ }^{29}$ Id at 202-03 (holding that the insurer failed to show a resolve to litigate prior to denying the insured's claim, and thus is not entitled to work product protection).

30 138 FRD 655, 663-64 (S D Ind 1991).

${ }^{31}$ Logan v Commercial Union Insurance Co, 96 F3d 971, 976 (7th Cir 1996), citing Binks Manufacturing Co v National Presto Industries, Inc, 709 F2d 1109, 1119 (7th Cir 1983) (internal citations omitted). See also Charles Alan Wright, Arthur R. Miller, and Richard L. Marcus, Federal Practice and Procedure: Civil $2 d \$ 2024$ at 338-39 (West 2d ed 1994) (explaining that since the 1970 amendments to Rule 26(b)(3), courts have generally looked at the particular facts present when determining if material was prepared in anticipation of litigation).

${ }^{32}$ See Stout v Illinois Farmers Insurance Co, 150 FRD 594, 601 (S D Ind 1993) (collecting cases); United States $v$ Davis, 636 F2d 1028, 1040 (5th Cir 1981).

${ }^{33}$ Travelers Indemnity Co v Allied-Signal, Inc, 124 FRD 101, 102 (D Md 1989). See also Carver $v$ Allstate Insurance Co, 94 FRD 131, 134-35 (S D Ga 1982) (holding that a substantial prospect of litigation was indicated by referral of the insured's fire loss claim to a senior representative). The "primary purpose" and "substantial prospect" formulations are merely two common examples of ad hoc, fact-intensive approaches. This Comment will use these examples as representatives of the ad hoc approach in the later analysis, because evaluation of a general ad hoc approach is difficult. For an endorsement of other fact-intensive approaches, see Brian Woodward, Note, Work Product Discovery in Insurance Litigation, 18 Ind L Rev 547, 559 (1985); Robert H. Oberbillig, Note, Work Product Discovery: A Multifactor Approach to the Anticipation of Litigation Requirement in Federal Rule of Civil Procedure 26(b)(3), 66 Iowa L Rev 1277, 1297 (1981). 
B. Bad Faith and the Substantial Need and Undue Hardship Question

Once a court determines that a document was prepared in anticipation of litigation, it must then decide whether the substantial need and undue hardship exception is satisfied. A party may attempt to establish substantial need in a variety of ways. ${ }^{34}$ One important pattern in insurance cases involves an insured arguing that his allegation that the insurer acted in bad faith establishes substantial need. ${ }^{35}$ Some courts agree that an allegation of bad faith alone constitutes substantial need because, for such a claim, the insurer's processing of the claim is critical, and the insured has no way of discovering how the claim was handled without access to the claim file. ${ }^{36}$ These courts argue that deny-

${ }^{34}$ For example, one well established line of cases finds substantial need and undue hardship when the claim file contains witness statements taken at the time of an accident. See, for example, Galambus v Consolidated Freightways Corp, 64 FRD 468, 473 (D) Ind 1974) (explaining that the "liberal policy" in favor of production of witness statements taken contemporaneously with the accident is justified because (1) the witness's memory is fresh at the time the statement is taken, and (2) the party seeking discovery may have been injured at the time of the accident and thus unable to investigate on his own at that time). See also Suggs $v$ Whitaker, 152 FRD 501, 509 (M D NC 1993) (allowing discovery of contemporaneous statements to insurer); Notes of Advisory Committee on 1970 Amendments to FRCP 26(b) (cited in note 8) (explaining that documents are likely to be discoverable when the witness has "given a fresh and contemporaneous account in a written statement while he is available to the party seeking discovery only a substantial time thereafter").

${ }^{35}$ Most states recognize a cause of action by an insured for a bad faith breach by his insurer. Allegations of bad faith against a first party insurer generally involve the denial of a claim. Bad faith may exist in situations where the insurer "denies liability knowing there is no rational principled basis for doing so." Logan, 96 F3d at 981, citing Erie Insurance Co $v$ Hickman, 622 NE2d 515, 520 (Ind 1993) (internal citations omitted). Compare Polselli v Nationwide Mutual Fire Insurance Co, 23 F3d 747, 751 (3d Cir 1994) (holding bad faith is "any frivolous or unfounded refusal to pay the proceeds of the policy"). Allegations of bad faith against a third party insurer, by contrast, often assert that the insurer has acted in bad faith by failing to defend a case against the insured adequately, or by refusing to accept a settlement offer that is advantageous to the insured. In the paradigm situation, the insurer refuses a settlement offer within the policy limits, and the ultimate liability turns out to be greater than the policy limits, leaving the insured personally liable for the excess. Where the original settlement offer is near the limits of the policy, the insurer may have little downside in refusing and seeing if it can do better; the insured bears the entire downside. See generally Lee $R$. Benton and G. David Johnston, Note, The Tort of Bad Faith: A Perspective Look at the Insurer's Expanding Liability, 8 Cumb L Rev 241 (1977).

${ }^{36}$ See, for example, Hall $v$ Goodwin, 775 P2d 291, 296 (Okla 1989) (explaining that absent discovery of the claim files, there is no other way to determine the basis upon which the insurer made its decision to deny the claim); Silva $v$ Fire Ins Exchange, 112 FRD 699, 699 (D Mont 1986) (same). If the substantial need and undue hardship exception is met in an insurance case, the court may need to consider how to "protect" opinion work product. See note 14 and accompanying text. In witness statement cases, see note 34 , this protection often involves the deletion of opinion work product-such as evaluative comments-from the witness statements before discovery is allowed. See Notes of Advi- 
ing access to the file in such cases could discourage allegations of bad faith, leaving insurers unaccountable. Other courts give less weight to a claim of bad faith, requiring some further showing of need to access materials insurers have prepared in anticipation of litigation. ${ }^{37}$ These courts fear that insureds may have an incentive to add allegations of bad faith to their complaints if doing so affords potential discovery advantages. ${ }^{38}$

The extent to which an allegation of bad faith establishes substantial need and undue hardship necessarily depends on what is otherwise protected. If most of the claim file is protected as in anticipation of litigation, substantial need to override that protection may occur relatively frequently because the insured will not otherwise have access to information necessary to make out the allegation of bad faith. But if only a few parts of the claim file are deemed in anticipation of litigation, a party seeking discovery should have more difficulty establishing a substantial need to obtain those few protected parts.

sory Committee on 1970 Amendments to FRCP 26(b) (cited in note 8) (explaining that courts will often find it necessary to order disclosure of a document with the mental impressions and subjective evaluations of lawyers, investigators, and claim agents deleted). Protecting opinion work product is a difficult issue when an allegation of bad faith is involved. Where an insured claiming bad faith has established substantial need for the claim file, the need is probably most substantial not for documents that contain facts about the underlying claim, but for documents that reveal how the insurer acted in handling the claim-documents that courts are particularly likely to consider opinion work product. Such cases put the "at issue" exception to the test, requiring courts to consider whether putting an insurer's behavior at issue by alleging bad faith circumvents the special protection of opinion work product. See note 14; Holmgren v State Farm Mutual Automobile Insurance Co, $976 \mathrm{~F} 2 \mathrm{~d}$ 573, 577 (9th Cir 1992) ("In a bad faith insurance claim settlement case, the 'strategy, mental impressions and opinions of [the insurer's] agents concerning the handling of the claim are directly at issue."), quoting Reavis $v$ Metropolitan Property and Liability Insurance Co, 117 FRD 160, 164 (S D Cal 1987). Some courts that allow an allegation of bad faith to establish substantial need also allow access to opinion work product, arguing that opinion work product is put directly at issue by the allegation of bad faith. See Reavis, 117 FRD at 164-65 (allowing discovery of claim files containing insurer's mental impressions, opinions, conclusions, and legal theories).

${ }^{37}$ See, for example, Logan, 96 F3d at 977 (" $[$ A] naked claim of bad faith cannot, without more, authorize a fishing expedition. ... The plaintiff must demonstrate some likelihood or probability that the documents sought may contain evidence of bad faith."); Closterman v Liberty Mutual Insurance Co, 1995 US Dist LEXIS 11356, *3 (E D Pa) ("[T]he mere allegation of bad faith does not entitle a plaintiff to work-product materials.").

${ }^{38}$ Some courts that find "substantial need" satisfied by an allegation of bad faith seek to protect such allegations from being strategically included by bifurcating or severing them from the remainder of the case, hence attempting to limit the usefulness of the additional discovery the allegation of bad faith allowed. See, for example, In re Bergeson, 112 F'RD 692, 697 (D Mont 1986); Corrente v Fitchburg Mutual Fire Insurance Co, 557 A2d 859, 860 (RI 1989). But see Ring $v$ Commercial Union Insurance Co, $159 \mathrm{FRD}$ at 653, 658 (M D NC 1995) (disfavoring bifurcation). See also Kevin M. LaCroix, Trial Bifurcation Provides Important Benefits to Insurers, 7 Inside Litig 15 (Oct 1993) (explaining the advantages to an insurer of bifurcation in "bad faith" litigation). 


\section{FUnCTIONAL CONSIDERATIONS IN APPLYING THE DOCTRINE AND FOUR ASSOCIATED COSTS}

This Part examines how the work product doctrine affects incentives for a party to do the socially optimal amount of pretrial preparation. It examines the value of an additional unit of preparation to the party and to society and discusses how the work product doctrine aligns those two interests. It then discusses four social costs that the work product doctrine may generate: divergence costs, missed sharing costs, administrative costs, and side effects costs.

\section{A. How the Work Product Doctrine Affects Incentives for Preparation}

1. The divergence of the value of preparation to society and to the litigant.

A litigant's incentives to undertake pretrial preparation do not necessarily give rise to an optimal level of preparation from society's point of view. ${ }^{39}$ There are several reasons why such a divergence might occur. First, a party will undervalue preparation that may reveal information that would benefit his opponent as well as himself and will accordingly do less preparation than society would prefer. ${ }^{40}$ Second, a party might do too little (or too much) pretrial preparation because the precedential value of the case is more (or less) important to him than to society generally. ${ }^{41}$ Finally, a party might do more preparation than is socially opti-

\footnotetext{
${ }^{39}$ A similar disparity exists with respect to the socially desirable amount of litigation. See generally Steven Shavell, The Fundamental Divergence between the Private and the Social Motive to Use the Legal System, 26(2) (pt 2) J Legal Stud 575 (1997).

${ }^{20}$ While information benefiting both parties could have social value in contributing to the "truth-seeking" function of litigation, the litigant. will not value information that may help his adversary. Allen, et al, argue that most litigation involves this sort of "joint production." They further theorize that it is in such situations that courts have been most willing to extend work product protection because absent protection the attorney is unlikely to undertake the pretrial investigation. Ronald J. Allen, et al, A Positive Theory of the Attorney-Client Privilege and the Work Product Doctrine, $19 \mathrm{~J}$ Legal Stud 359, 385-86 (1990).

11 See Easterbrook, 1981 S Ct Rev at 359-61 (cited in note 16) (arguing that society's interest in the creation of information in litigation is primarily to further "rule-creation" and "rule-enforcement," while the motivation of many litigants focuses on the individual case). But see Thornburg, $77 \mathrm{Va} \mathrm{L} \mathrm{Rev} \mathrm{at} 1562$ (cited in note 10) (arguing that repeat players have an incentive to "spend" an amount of money disproportionate to the value of a particular lawsuit because they stand to gain in future lawsuits from the rules made in the first suit).
} 
mal because he overvalues the "stakes-dividing" function of litigation-a function that has a relatively low social value. ${ }^{42}$

2. When a litigant will do an additional unit of preparation.

A hypothetical litigant, A, will do an additional unit of preparation whenever the expected net benefit to $A$ of doing the work is positive. The expected net benefit to $A$ is the difference between the expected value of the additional information to $A$ and the expected present cost to $A$ of doing the work. The net benefit also reflects any value $\mathrm{A}$ expects his opponent, $\mathrm{B}$, to receive from A's preparation, as well as the value of A's lost opportunity to wait and see if $B$ will do the preparation first and be forced to share the results with $\mathrm{A}$.

Accordingly, the likelihood that a court will order A to turn over certain trial preparation materials during discovery affects A's expected net benefit. If $A$ expects the court to adopt a no sharing rule, the expected value of preparation to $A$ generally increases. This increase is attributable to three factors. First, information may be more valuable to a party if the opposition does not have it. ${ }^{43}$ Second, with no sharing, A's lost opportunity to wait and see if $B$ will do the preparation and be forced to share with $A$ is of little value. ${ }^{44}$ Third, A's expectation that his preparation will not have to be shared means that the expected value to $B$ of A's preparation will be small. ${ }^{45}$

In contrast, if $\mathrm{A}$ expects a sharing rule, A's expected net benefit from his preparation may decrease. First, if A expects to have to share, he may expect that B's case will be strengthened by the availability of A's work product. Second, A may believe that he will be able to get the desired information "for free" from B without doing the preparation himself. Under these circumstances, undertaking preparation may have a significant opportunity cost for A.

Given that A's expectation as to whether he must share his preparation may impact A's net expected benefit, the anticipated discovery rule may determine whether $A$ does an additional unit

\footnotetext{
42 See Easterbrook, 1981 S Ct Rev at 359-60 (cited in note 16) ("The enterprise of litigation usually is principally a fight over spilt milk.").

${ }^{23}$ This increment has been referred to as a "secrecy value." See Thornburg, $77 \mathrm{Va} \mathrm{L}$ Rev at 1547 (cited in note 10).

"This conclusion assumes that the court will also apply the "no sharing" rule if B does the preparation.

${ }^{4}$ Even if the trial preparation materials cannot be accessed directly, $B$ may still derive some benefit from A's preparation because of the ability to discover the facts revealed by the preparation via depositions. See note 12 and accompanying text.
} 
of preparation. Two distinct scenarios are possible. In the first scenario, A will not do the work if he expects to have to share his preparation with $\mathrm{B}$, but $\mathrm{A}$ will do the work if he expects his preparation to be protected. In the second scenario, $A$ will not do the work if he expects not having to share the preparation, but will do the work if he expects that the preparation will be shared. It is a fundamental assumption of the work product doctrine that the former situation is the norm: the work will be more valuable to $\mathrm{A}$ if he does not have to share it. ${ }^{46}$

In some situations, however, the expected rule will not decide whether the preparation gets done. A will do some preparation regardless of what discovery rule he expects. This preparation will increase A's expected net benefit whether or not the work will have to be shared. Conversely, A will decline to undertake some preparation regardless of the expected discovery rule. Whether or not A expects sharing, such preparation will not increase A's expected net benefit.

3. When society wants an additional unit of preparation.

Society wants A to do an additional unit of preparation when the net expected benefit to society is positive. Whether this benefit is positive reflects a number of factors. One important factor is whether society expects the preparation to produce information that will contribute to the accurate resolution of the case. ${ }^{47}$ However, some preparation expected to lead to accurate resolution of the case may be undesirable for other reasons. For example, society may not benefit if the preparation leads to an undesirable one-sidedness of information, produces delay, or is expensive to carry out. ${ }^{48}$

The value of A's preparation to society varies depending on the perceived likelihood that a court will force A and B to share their preparation during discovery. If the litigants expect a no sharing rule, they may each prepare the same work independently, resulting in wasteful costs due to duplication. Although the duplicated efforts may enhance the strength of the litigants' cases, duplication does not enhance truth-seeking or important precedent-setting, and thus is not socially beneficial. ${ }^{49}$ Further,

\footnotetext{
${ }^{46}$ While this assumption accords with our intuition in most situations, there will be settings where it may not hold. We will see one such setting in Part IV.

${ }^{47}$ See generally Louis Kaplow, The Value of Accuracy in Adjudication: An Economic Analysis, 23 J Legal Stud 307 (1994).

${ }^{4}$ A's expenses may be passed on to society in ways that cause distributional concerns.

${ }^{9}$ Concerns regarding duplication might be mitigated if there is a likelihood of bar-
} 
society might prefer that B do the work instead of A if B can do the preparation better or at a lesser cost.

4. Work product protection as a tool for aligning the litigant's incentives for preparation with society's desires.

Given that an individual's benefit from pretrial preparation may diverge from society's, courts should apply the work product doctrine to encourage $A$ to do an additional unit of work when society wants $A$ to do so and to maximize the benefit that society receives from each unit of preparation that $A$ does. As noted above, preparation can be grouped into three categories: preparation A will not do regardless of the sharing rule, preparation A will do regardless of the sharing rule, and preparation for which the choice of sharing rule will determine whether $A$ does the work.

In the first and second situations, the choice of discovery rule has no effect on behavior. Whether a "sharing" or "no sharing" rule applies, A will not do the preparation in the first situation and will do the preparation in the second situation. In the second situation, however, the expected discovery rule will affect the value of A's work to society. Because A will do the work in any case, society benefits most from a discovery rule that maximizes the value of A's work to society. If A must share his work with B, society will benefit because, all else equal, sharing of information has a positive value to society. Accordingly, under circumstances where A will do the preparation regardless of the expected discovery rule, courts should adopt a sharing rule.

In the third category, where A's decision to do an additional unit of preparation turns on the expected discovery rule, the choice of rule is critical. As noted above, the usual assumption is that A will do the work if he expects a no sharing rule but not if he expects a sharing rule. ${ }^{50}$ If the usual assumption holds, society's choices in this third category are to encourage $A$ to do the work by implementing a "no sharing" rule, or to encourage A not to do the work by implementing a sharing rule. No rule will lead A to do the work and share it. A will do the work and share only if he incorrectly expected that the rule would be "no sharing."

gained-for sharing arrangements between the litigants.

${ }^{50}$ See note 46 and accompanying text.

${ }^{51}$ Thus, use of a sharing rule to avoid "duplication" may not have the desired effect. If the choice of rule determines whether the litigant does the work, duplication is avoided only by avoiding the preparation altogether. Conversely, a "no sharing" rule will not necessarily lead to duplication. Parties are free to negotiate reciprocal sharing arrangements to avoid duplication. Such arrangements are most likely to occur where each party has in- 
Determining which of the two available options is preferable may be difficult, as the decision requires an advance determination whether "not doing" or "doing but not having to share" would be preferable to society. ${ }^{52}$

\section{B. Costs to Consider in Applying the Doctrine}

\section{Four types of costs.}

Society should interpret the work product doctrine to bring A's incentives for preparation in line with society's desires, and to achieve maximum utility from any preparation done. In devising the most efficient application of the doctrine, courts must consider four possible social costs: "divergence" costs, "missed sharing" costs, "administrative" costs, and "side effects" costs. The best approach will minimize the aggregate of these costs.

Divergence costs arise when a rule fails to eliminate the divergence between the litigant's and society's preferences and thus does not achieve the optimal amount of preparation. Divergence costs often result when a sharing requirement discourages socially valuable preparation. Similarly, a rule's failure to make optimal use of completed preparation may be costly. Where preparation would be done even if it will have to be shared, the work product doctrine should require sharing. Failure to do so leads to "missed sharing" costs.

Even a rule that effectively encourages the socially optimal amount of work and the optimal use of work that is done may be undesirable due to concerns about administrative costs and side effects. Administrative costs arise when courts must undertake time-consuming factual evaluations to apply the rule. Consequently, society may adjust its preferred amount of preparation in order to avoid these high costs of administration. In addition, an otherwise desirable rule might generate costly side effects, including discord with other areas of the law, or undesirable behavior by potential litigants in seeking to conform to the rule. ${ }^{53}$

formation attractive to the other side.

${ }^{52}$ In situations where the "usual" assumption does not hold, society faces a different choice. There, a "no sharing" rule will discourage preparation, and a sharing rule will encourage it. We will encounter a situation in Part IV where the usual assumption may not hold.

${ }^{53}$ Litigant behavior is undesirable if it generates unnecessary costs. Examples include unnecessary involvement of legal staff or inefficient claims processing procedures. If such "undesirable" strategies for conforming to the rule are effective, they may reduce the degree to which litigants' incentives for preparation accord with societal desires. In addition to increasing divergence costs, such strategies may involve behavior that is independently socially undesirable, and that society would want to discourage in its own 
2. Rule $26(\mathrm{~b})(3)$ as a mechanism to avoid these costs.

Courts facing work product questions are not free to start with a clean slate and come up with a rule that minimizes the four costs. Courts must proceed in the context of Rule 26(b)(3) or a state counterpart. However, Rule 26(b)(3) may operate as a rough mechanism for producing sharing or no sharing in ways that tend to limit divergence costs and missed sharing costs. How well the Rule accomplishes this goal, and how well it avoids administrative costs and side effects in so doing, depends on how courts interpret the Rule in specific contexts. An understanding of the potential costs involved may allow courts to apply the work product doctrine in the most beneficial way.

The "anticipation of litigation" requirement may be viewed as an imprecise measure of whether the amount of preparation is likely to depend on the expected sharing rule. If a document is deemed not to have been prepared in anticipation of litigation, the presumption is that it would be prepared regardless of the interpretation of the work product doctrine. Protection is thus unnecessary, and a sharing rule is appropriate to avoid missed sharing costs. In contrast, when the document is deemed to have been prepared in anticipation of litigation, the presumption is that the nature of the sharing rule will determine whether the document is prepared. Hence, society should implement the rule purposively to encourage or discourage preparation as desired. Society does so by imposing a no sharing rule that allows override by a demonstration of substantial need and undue hardship.

The "substantial need" exception may thus provide a mechanism, albeit imperfect, by which courts can purposively encourage or discourage preparation in situations where the rule matters. ${ }^{54}$ The substantial need exception may also function as a cor-

right. Hence, there are side effects costs.

${ }^{54}$ The special treatment of opinion work product is another mechanism that encourages preparation for which the sharing rule is likely to matter. Rule 26(b)(3) adopts a no sharing rule for most or all opinion work product. This rule is consistent with a judgment that the sharing/no sharing rule will often determine whether such preparation gets done. Assuming the rule matters, society might prefer that opinion work product be done even if not shared because it has "high value added" from a societal standpoint in terms of achieving an accurate result. To encourage the socially beneficial, precedent-creating function of litigation over the stakes-dividing function, Judge Easterbrook has suggested that the work product doctrine should encourage the creation of "productive or planning information" versus the application of existing information to the facts of the case. Opinion work product, such as crafting of strategy, may constitute such "productive or planning" activity. Easterbrook, $1981 \mathrm{~S}$ Ct Rev at 361 (cited in note 16). In addition, there is little reason to require sharing of opinion work product to avoid duplication: evaluations and analyses are much less likely to be duplicative than factual investigations. Likewise, society is unlikely to wish to discourage A's preparation of opinion work product because 
rection for the fact that the "anticipation of litigation" requirement does not perfectly identify and require sharing of documents for which the rule does not matter..$^{5}$

\section{ChOOSING RULES FOR CLAIM FILES: MINIMIZING COSTS WITH THE DENIAL PRESUMPTION}

This Part evaluates the approaches courts have used in interpreting the work product doctrine in the insurance context according to the four costs discussed above. ${ }^{56}$ There are five common approaches: (1) the ordinary course of business exception; (2) the broad protection approach; (3) the direction of counsel rule; (4) the denial presumption; and (5) the ad hoc approach. ${ }^{57}$ As stated above, the optimal approach will minimize divergence costs by giving insurers incentives to do the optimal amount of preparation, minimize missed sharing costs by insuring maximum utility from preparation that is done, minimize administrative costs, and minimize side effects.

In evaluating how judicial approaches fare in terms of the above costs, adequate attention must be given to the bad faith issue. The optimal approach to the anticipation of litigation threshold may depend on the rule governing claims of bad faith, and the optimal approach to the bad faith issue may depend on the chosen anticipation of litigation rule. The analysis will reveal that for cases involving first party insurance, the best approach utilizes a denial presumption, accompanied by a rule that an allegation of bad faith does not automatically establish substantial need.

$B$ could do it better.

${ }^{65}$ This role of the substantial need exception is well illustrated by cases allowing discovery of contemporaneous witness statements. See note 34. Because of the value of such statements, they are likely to be taken regardless of whether the insurer expected that they would have to be shared if litigation ensued. Hence to avoid missed sharing costs, a sharing rule is appropriate. Yet in many cases, such documents will be deemed to have been prepared in anticipation of litigation, and hence protected. The substantial need exception is a second chance to reach the "correct" result: a sharing rule.

The substantial need exception performs this corrective role imperfectly because the factors relevant to the substantial need determination may differ from those relevant to whether a litigant does a certain amount of preparation. For example, when an insurer decides whether to undertake certain preparation, he will consider whether the work product doctrine protects such preparation and whether the preparation is valuable even if unprotected. By contrast, substantial need depends not only on the nature of the preparation, but also on the circumstances of the particular plaintiff, which the insurer may not know when it is making decisions about preparation.

${ }^{56}$ See Part III.B.1.

${ }^{57}$ See Part II.A. 


\section{A. Divergence Costs}

As Part III demonstrated, divergence costs arise when courts interpret the work product doctrine in a manner that leads to an amount of preparation not in accordance with what society wants. This situation usually arises where a sharing requirement discourages valuable preparation. ${ }^{58}$ In particular, divergence costs are likely to occur when a court imposes a blanket sharing requirement under circumstances in which litigants' preparation efforts are sensitive to the sharing rule.

The denial presumption approach performs relatively well in terms of divergence costs. The denial presumption holds that any material prepared by the insurer prior to the insurer's denial of the contested claim is not protected by the work product doctrine. ${ }^{59}$ As long as the unprotected pre-denial preparation would have been undertaken by the insurer regardless of the expected discovery rule, this lack of protection will not discourage the preparation; hence, divergence costs are avoided. If, however, litigation is contemplated well before denial, a discovery rule that forces the insurer to turn over documents prepared prior to denial may discourage pre-denial preparation..$^{60}$ Under these circumstances, the denial presumption may lead to divergence costs. ${ }^{61}$

ss The court in Stout $v$ Illinois Farmers Insurance Co pointed out that the "preparation" the work product doctrine intends to encourage is trial preparation, not the insurers' preparation of claim files generally. The court concluded that denouncing an interpretation of the rule because it leads to poor quality claims processing is inappropriate. 150 FRD 594, 603 (S D Ind 1993).

While technically correct, this observation may have little consequence because of the overlap between claims processing and trial preparation. Encouraging good trial preparation in insurance cases is closely related to encouraging good investigation of claims. Nonetheless, the point is well taken that the work product doctrine is not intended to serve as a vehicle for achieving general insurance reform.

${ }_{59}$ See notes 27-29 and accompanying text.

$\infty$ This situation often occurs in cases in which insurers know there is a high risk of litigation. See, for example, Raso v CMC Equipment Rental, Inc, 154 FRD 126, 128-29 (E D Pa 1994) (holding that an investigation undertaken by an insurer of a catastrophic crane accident was in anticipation of litigation, even though the injured party had yet to file a claim); Ring $v$ Commercial Union Insurance Co, 159 FRD 653, 656-57 (M D NC 1995) (holding that an investigation undertaken by an insurer following a suspected arson was in anticipation of litigation, even though the insurer had yet to deny the claim). Applying the denial presumption in these cases would have resulted in forced sharing. If the insurer chose to forego preparation rather than share, forced sharing might have caused divergence costs. However, insurers are likely to investigate carefully most serious accidents regardless of the sharing rule, so that requiring sharing will produce only modest divergence costs, while affording protection (as in Raso and Ring) could lead to substantial missed sharing costs.

61 The fear of an allegation of bad faith by the insured may mitigate the insurer's tendency to forego such preparation, however, thus reducing concerns about divergence costs. See Part IV.E. 
Other approaches yield divergence costs comparable to that of the denial presumption. Under the primary purpose formulation of the ad hoc approach, courts hold that materials are discoverable so long as the primary purpose of their preparation was not litigation. Even when litigation was a secondary purpose, this approach requires the insurer to turn over its materials. However, the expected sharing rule may determine whether preparation is done even though litigation is only a secondary purpose. By requiring sharing in situations where the rule may be decisive, this formulation may discourage valuable preparation, giving rise to divergence costs.

The direction of counsel approach encounters similar difficulties. It is quite conceivable that the preparation efforts of nonlegal personnel may be sensitive to the sharing rule they expect to face at trial. For example, nonlegal personnel might continue to supervise the claim investigation well after litigation becomes likely, and the discovery treatment they expect may accordingly influence the nature and scope of their investigation. Imposing a sharing rule because of lack of counsel involvement may discourage such preparation, giving rise to divergence costs. ${ }^{62}$

The ordinary course of business exception may also lead to divergence costs. For insurers, unlike many businesses, ordinary business includes the possibility of litigation. ${ }^{63}$ Many of the documents that the ordinary course of business exception would require to be shared are documents which an insurer might not create if it expects a sharing rule. Fear that a sharing rule might be imposed in potential litigation could discourage the preparation of such documents, giving rise to divergence costs.

Only two approaches give rise to lower divergence costs than does the denial presumption approach: the broad protection rule and the "substantial prospect of litigation" formulation of the ad hoc approach. Under the broad protection rule, sharing is rarely

\footnotetext{
62 From the text of Rule 26(b)(3) alone, it is difficult to argue that such costs are unavoidable. "Anticipation of litigation" does not explicitly require the direction of counsel. In fact, the rule's express inclusion of documents prepared by non-counsel makes the reintroduction of direction of counsel as a necessary component of "anticipation of litigation" in insurance cases rather awkward. See Spaulding $v$ Denton, 68 FRD 342, 345 (D Del 1975) (explaining that Rule 26(b) gives "nonlawyers equal status with lawyers for the purpose of 'in anticipation of litigation"').

${ }^{\infty}$ Some courts and commentators have recognized this characteristic of insurers. See, for example, United States v AT \& T, 86 FRD 603, 628 (D DC 1979) ("For many organizations, litigation is an integral part of their business, for example liability insurance companies . . . ."); Robert D. Stokes, Note, Discovering Investigative Reports Under the Work Product Doctrine, 34 Baylor L Rev 156, 165 (1982) (noting that for insurance companies, the ordinary course of business entails constant preparation for litigation).
} 
required. Consequently, preparation is not discouraged and divergence costs are correspondingly low. Similarly, most cases that do not involve a substantial prospect of litigation, the sharing rule is unlikely to determine an insurer's degree of preparation. ${ }^{64}$ Requiring sharing in such instances is therefore unlikely to discourage a significant amount of preparation, keeping divergence costs low.

\section{B. Missed Sharing Costs}

As Part III discussed, missed sharing costs arise when a court's application of the work product doctrine fails to force sharing of documents under circumstances where requiring sharing would not discourage preparation. ${ }^{65}$

Both the denial presumption approach and the ordinary course of business exception approach give rise to low missed sharing costs. The denial presumption provides for "no sharing" only for preparation done after coverage is denied. The main purpose of postdenial preparation is readying for litigation, however. To require sharing could well discourage such preparation, so there is little missed sharing.

The ordinary course of business exception approach also yields low missed sharing costs. Under this approach, a court will deem much of the claim file to be created in the ordinary course of business. Accordingly, the court will require that much of the file be shared; hence there will be little missed sharing.

The other approaches give rise to greater missed sharing costs. Under the direction of counsel approach, no sharing is required for documents prepared at the direction of counsel. There will inevitably be some documents prepared at the direction of counsel, however, that would be prepared regardless of the sharing rule. Unnecessarily protecting these documents yields missed sharing costs.

The primary purpose formulation of the ad hoc approach also creates missed sharing costs. Under this approach, courts require that work product be shared unless the primary purpose of the

${ }^{54}$ This generalization does not deny that this sharing rule will have some impact on insurer behavior before there is a substantial prospect of litigation. Even if litigation is not contemplated with regard to a given claim, the sharing rule may have a structural impact on the processing of that claim via general procedures adopted in light of past interpretations of the work product doctrine in similar cases. If the stakes of the case are high enough, the mere fear of litigation may make the discovery rules important to the insurers' behavior regardless of how likely such litigation is to occur.

${ }_{65}$ Missed sharing costs in insurance cases are unlikely to be reduced by negotiated sharing agreements. An individual opposing an insurance company will have little in the way of "documents or tangible things" for which the insurer is willing to bargain. 
work was to prepare for litigation. Although the choice of sharing rule will often affect whether a document whose primary purpose is litigation gets created, some of this preparation will be so critical to the insurer that the insurer will do it regardless of the expected sharing rule. By failing to require sharing of such documents, this approach gives rise to missed sharing costs.

Missed sharing costs are even higher for the substantial prospect of litigation formulation of the ad hoc approach. Under this approach, courts require an insurer to share the claim file unless there was a substantial prospect of litigation. For some claims, there may be a substantial prospect of litigation from the outset, but the insurer would undertake some sort of investigation regardless of the expected sharing rule. ${ }^{66}$ Hence, the substantial prospect approach will fail to require sharing when sharing is possible, leading to high missed sharing costs.

Finally, the broad protection approach yields the highest missed sharing costs. Protecting almost all of the file from sharing inevitably results in extensive missed sharing. Work product protection is intended for the sort of documents that might cease to be generated if not protected. Certainly, there will be many documents that would be prepared regardless of the expected interpretation of the work product doctrine; thus, broad protection creates very high missed sharing costs. ${ }^{67}$

\section{Administrative Costs}

Administrative costs for the denial presumption approach are low. Applying the denial presumption rule simply requires a court to determine when a claim was denied, and protect all work done thereafter. Courts are unlikely to have a difficult time deciding the point at which coverage is denied; thus, administrative costs are limited..$^{68}$

\footnotetext{
${ }^{66}$ Carver's holding that a substantial prospect of litigation began when the claim was referred to senior personnel leaves much room for error in this regard. See note 33; Carver, 94 FRD at 134-35. After referral to senior personnel, much of the investigation may still be fairly routine, and may be carried out regardless of the expected discovery treatment.

67 The "anticipation of litigation" language surely does not make this reading unavoidable. In an age when the possibility of litigation often may be at the back of many minds, arguing that "anticipation of litigation" includes any possibility of litigation may lead to the conclusion that every document in every case (not just insurance cases) is protected.

${ }^{68}$ But see Harper, 138 FRD at 665 , where the insurer argued that a claim was "denied" when the insurer's decision was recorded rather than when the decision was conveyed to the insured.
} 
The broad protection rule also yields low administrative costs, because basically everything in the claim file is protected. Courts utilizing this approach could handle discovery requests pertaining to the claim file easily and without incurring significant administrative costs: they would deny most such requests out-of-hand. ${ }^{69}$

The "direction of counsel" approach and the "ordinary course of business" approach may involve higher administrative costs. The direction of counsel rule, although sounding like a bright line rule, is not as simple as one might imagine. Courts will have to resolve the question of just how much involvement of counsel is enough to afford protection, giving rise to administrative costs. ${ }^{70}$

For the ordinary course of business approach, administrative costs will be low if most or all of the claim file is habitually deemed to have been prepared in the ordinary course of business. If a court undertakes a more individualized inquiry, however, administrative costs will increase. ${ }^{71}$

Finally, the ad hoc approach has high administrative costs, regardless of the specific formulation used. Under this approach, courts must carefully examine the facts of each case rather than employ a "cutoff" for what constitutes anticipation of litigation in the insurance context. This fact-specific examination will inevitably yield high administrative costs.

\section{Side Effects}

At first glance, the denial presumption appears to have a troublesome side effect: Affording work product protection only to portions of the claim file generated after the claim is denied might prompt insurers to deny a claim early, and then investigate whether the denial was appropriate, all the while under the shield of work product protection. Given the possibility of an allegation of bad faith, however, insurers are unlikely to respond to the denial presumption rule in this way. If the claim file is sparse

${ }^{69}$ The administrative costs of the denial presumption and the broad protection rule are low for the insurers as well. Insurers under these rules can accurately predict whether their preparation would have to be shared. Compare Upjohn Co $v$ United States, 449 US 383, 393 (1981) ("An uncertain privilege, or one which purports to be certain but results in widely varying applications by the courts, is little better than no privilege at all.").

${ }^{70}$ Administrative costs for insurers under the direction of counsel rule are high as well, because they will face uncertainty regarding what courts will consider to be "direction of counsel," and will struggle to predict what work will be protected.

${ }^{71}$ In this case, administrative costs for insurers rise as well, because they will not know with certainty whether a document they have prepared is in the "ordinary course of business.” 
at the time of the denial, the insured has a strong claim that the insurer acted in bad faith. The availability of a cause of action thus discourages insurers from reacting to the denial presumption by denying claims prematurely, with the result that the side effects of the denial presumption remain low.

In contrast, the other approaches to the work product doctrine generate a variety of potentially costly side effects. The ad hoc approach will give rise to side effects if insurers alter their behavior in the hopes of falling within the rule. For example, insurers may try to appear as though they are anticipating litigation by involving senior personnel or legal staff in the investigation of the claim, or by generating "I'm suspicious about this claim" memos.

Unlike the ad hoc approach, the broad protection approach generates no potential side effects related to undesirable alterations in insurer behavior to comply with the rule, because virtually everything is already protected. The lack of access to claim files, however, may have the troublesome side effect of discouraging suits against insurers, leaving insurers unaccountable.

The ordinary course of business approach yields two types of potential side effects. First, insurers may attempt to make claim investigations seem extraordinary so as to fall outside the exception. Such behavior would cause unnecessary expense and delay in the resolution of claims. Second, undesirable side effects may arise from the growing sense in the legal community that in the insurance context and elsewhere, the ordinary course of business approach is incompatible with the rule's protection of materials prepared in anticipation of litigation. ${ }^{72}$

The direction of counsel approach has very high side effects. First, a rule that shields only preparation done at the direction of counsel is likely to encourage insurers to rely more heavily on attorneys, even for tasks that nonattorneys can perform, increasing the cost of insurance with little coincident social gain. Second, judicial reliance on this approach in the insurance context is inconsistent with the application of the "anticipation of litigation" requirement in other contexts, where courts have not found direction of counsel to be a critical element. ${ }^{73}$ This lack of coherence in the law may lead to social costs because of both uncertainty

${ }^{72}$ See, for example, Thomas Wilson, Note, The Work Product Doctrine: Why Have an Ordinary Course of Business Exception?, 1988 Colum Bus L Rev 587, 600 (arguing that, in contrast to judicial determinations that materials prepared in the ordinary course of business are necessarily not in anticipation of litigation, the two are not mutually exclusive).

${ }^{73}$ See note 62. 
among the parties and decreased confidence in the law due to its apparent inconsistency.

\section{E. The Impact of a Possible Allegation of Bad Faith}

The strengths and weaknesses of the five approaches to the anticipation of litigation requirement may be either magnified or mitigated when the availability of complaints of bad faith by the insured against the insurer is considered. The discovery treatment of such allegations may have significant effects on all four costs of employing the work product doctrine.

The effect of complaints of bad faith on administrative costs is relatively straightforward. Complaints of bad faith generally increase costs of judicial administration. For example, a rule may yield low administrative costs in determining whether the "anticipation of litigation" requirement is met, but may necessitate high administrative costs when the court must determine whether an insured's allegation of bad faith gives rise to "substantial need."

The availability of allegations of bad faith also introduces two troublesome side effects. In framing substantive and procedural rules to govern complaints of bad faith, courts must seek to avoid both encouraging spurious charges of bad faith by making claims of bad faith too attractive to litigants and leaving insurers unaccountable by making actions for bad faith excessively difficult to bring. The impact of these side effects will depend on whether an allegation of bad faith automatically establishes substantial need and on the "anticipation of litigation" threshold.

The effect of potential complaints of bad faith on divergence and missed sharing costs is more complicated. Materials that are considered for the substantial need exception have already been deemed to have been prepared in anticipation of litigation. To the extent that the insurer's decision to undertake preparation depends on the sharing/no sharing rule, whether or not a bad faith allegation is considered to establish substantial need and necessitate sharing will determine whether such preparation will be done. The usual presumption is that a sharing rule will discourage preparation. ${ }^{74}$

The usual presumption does not necessarily hold in this context, however. The fear of sharing a claim file in an action for bad faith will not discourage an insurance company's preparation. On the contrary, an insurer is likely to do more. An insurer knows that if he does little work on a claim, and the court allows discov-

\footnotetext{
${ }^{4}$ See note 46 and accompanying text.
} 
ery of the claim file, the plaintiff could use the insurer's minimal efforts as evidence that the insurer lacked a rational basis for denying the claim, giving rise to potential bad faith liability. ${ }^{75}$ Thus, the knowledge that sharing might be required in an action for bad faith could lead insurers to do more preparation, not less. A sharing rule may actually encourage preparation by the insurer if he believes such preparation will protect him from bad faith liability. ${ }^{76}$ At the very least, the threat of a complaint of bad faith mitigates concerns that a sharing rule will discourage preparation, and escalates concerns that a no sharing rule will lead to missed sharing costs.

F. The Effect of a Possible Complaint of Bad Faith on the Costs of the Courts' Five Approaches

The possibility of a complaint of bad faith may affect the costs generated by the five approaches to anticipation of litigation. For some approaches, allowing an automatic establishment of substantial need upon an allegation of bad faith is less costly; for other approaches, refusing such an establishment is preferable. Accordingly, the costs generated by the possibility of a claim of bad faith vary significantly depending on the underlying approach to anticipation of litigation.

For the denial presumption approach, the primary purpose formulation of the ad hoc approach, and the ordinary course of business approach, costs do not increase significantly when the court considers a claim of bad faith. Each of these approaches allows the bad faith question to be handled with limited administrative costs. These approaches also limit two potential side effects: encouraging spurious complaints of bad faith and leaving insurers unaccountable by overdeterring allegations of bad faith.

These approaches limit administrative costs and side effects at the substantial need stage because the information most important to parties alleging bad faith is already subject to discovery at the anticipation of litigation stage. For a first party complaint of bad faith, the most relevant portions of the claim file are those revealing insurer behavior prior to denial of the claim. ${ }^{77}$ Under each of these three approaches, most pre-denial informa-

\footnotetext{
"5ee note 35 .

76 This reasoning does not apply to preparation contemplated by the insurer during time periods not pertinent to an allegation of bad faith. During such time periods, the threat of an allegation of bad faith has no deterrent effect and the usual assumption that a sharing rule could discourage preparation is more likely to hold.

7 This result occurs because the claim is usually one of bad faith denial, for which the insurer's pre-denial investigation is most relevant. See note 35.
} 
tion will be deemed not to have been prepared in anticipation of litigation, and will be discoverable regardless of whether the insured brings a claim of bad faith. Under the denial presumption approach, the insured will have access to all pre-denial information at the anticipation of litigation stage. Under the primary purpose formulation of the ad hoc approach, the insured will have access to most pre-denial preparation, because these documents are most likely for purposes of making the claim decision rather than for purposes of litigation. Finally, under the ordinary course of business approach, the insured will have access to most pre-denial information, which generally falls under the ordinary course of business classification.

Because these approaches grant generous discovery at the anticipation of litigation stage, courts should not automatically allow a party who claims bad faith access to additional information. By such a refusal, courts avoid both potential side effects. Plaintiffs will already have enough of the claim file to assess whether the insurer has acted in bad faith and to hold the insurer accountable. In addition, because a complaint of bad faith will not afford an automatic discovery advantage, plaintiffs will have no incentive to make meritless allegations of bad faith.

The refusal to allow an allegation of bad faith to satisfy the substantial need and undue hardship exception automatically limits administrative costs of these approaches at the substantial need stage as well. A plaintiff is always free to undertake a direct demonstration of substantial need. Because most of what a claimant of bad faith needs is discoverable at the anticipation of litigation stage, however, such showings of substantial need will be relatively uncommon. ${ }^{78}$

The broad protection approach, direction of counsel approach, and substantial prospect of litigation formulation of the ad hoc approach handle the issue of bad faith less effectively than the above approaches. Each of these approaches leads to significant additional costs when the possibility of a claim of bad faith is considered, primarily because what is shared at the anticipation of litigation stage may not be what a party who makes a claim of bad faith needs. Costly adjustment at the substantial need stage may therefore be necessary.

Consider first the impact of potential complaints of bad faith under the broad protection rule. According to this approach, an

\footnotetext{
${ }^{78}$ See, for example, Squealer Feeds $v$ Pickering, 530 NW2d 678, 688 (Iowa 1995) (finding that where insured had access to pre-denial materials, substantial need for postdenial materials had not been demonstrated).
} 
insured is denied access to materials relating to even the most routine investigations by the insurer. Because the whole file is protected, demonstrating substantial need is the only way to obtain any of the file. Without access to any of the insurer's file, it may be extremely difficult for a plaintiff ever to establish a complaint of bad faith against an insurer. ${ }^{79}$ Thus, the broad protection rule may have the troublesome side effect of overdeterring valid complaints of bad faith. Unfortunately, the obvious solution of allowing an allegation of bad faith to establish substantial need automatically would generate side effects. Adopting an approach that yields automatic sharing for causes of action alleging bad faith but no sharing for other causes of action-such as recovering on a policy contract-is likely to encourage plaintiffs to bring frivolous complaints of bad faith strategically in order to get an advantage during discovery. ${ }^{80}$ Regardless of whether a claim of bad faith establishes substantial need, such a complaint increases administrative costs under the broad protection approach. The court must either determine which parts of the file become automatically accessible as a result of the complaint of bad faith or conduct a case-specific "substantial need" inquiry. ${ }^{81}$

The direction of counsel rule also threatens to yield substantial costs when an allegation of bad faith is raised. This approach may leave insurers unaccountable because they could involve counsel at an early stage, thereby protecting most of the claim file. Courts might counteract this undesirable side effect by holding that an allegation of bad faith alone conclusively establishes substantial need. As with the broad protection approach, however, this bright-line rule will increase the number of frivolous allegations of bad faith, will produce significant administrative costs, and will decrease insurers' ability to predict what will be protected.

The substantial prospect of litigation formulation of the ad hoc approach raises similar concerns about increased social costs. While the insured automatically gains access to the parts of the claim file prepared when litigation was not a substantial prospect, the complaint of bad faith may well turn on the insurer's

${ }^{79}$ See Folmgren $v$ State Farm Mutual Automobile Insurance Co, 976 F2d 573, 576-78 (9th Cir 1992); Tackett $v$ State Farm Fire and Casualty Insurance Co, 653 A2d 254, 26162 (Del 1995).

${ }^{80}$ The plaintiffs' motives may not be wholly improper: without an allegation of bad faith, the insured has minimal access to the claim file, and may honestly-but wronglybelieve he has a valid action for bad faith.

${ }^{81}$ The bad faith issue also increases administrative costs for the insurer. Although the insurer may expect that a broad protection rule will protect the entire file, the risk of discoverability in a bad faith action reduces the certainty of that protection. 
behavior after litigation became a substantial prospect and before the claim was denied. Hence, courts might be tempted to allow a plaintiff to qualify for the substantial need exception automatically in order to ensure that complaints of bad faith are not systematically disadvantaged. But as previously demonstrated with the broad protection and direction of counsel approaches, this strategy would lead to an increased number of allegations of bad faith and to increased administrative costs.

G. The Best Approach: Denial Presumption

The table below summarizes the social costs generated by each of the available judicial interpretations of the work product doctrine. For each approach to the "anticipation of litigation" requirement, the table represents the costs the approach generates if discovery requests in actions for bad faith are handled in the least costly way. Because the possibility of complaints of bad faith may yield increased administrative costs and side effects, these costs are separated into those incurred at the anticipation of litigation stage and those generated in conjunction with the bad faith issue.

\begin{tabular}{|l|l|l|l|l|}
\hline & $\begin{array}{l}\text { Divergence } \\
\text { Costs }\end{array}$ & $\begin{array}{l}\text { Missed } \\
\text { Sharing } \\
\text { Costs }\end{array}$ & $\begin{array}{l}\text { Administrative } \\
\text { Costs }\end{array}$ & Side Effects \\
\hline $\begin{array}{l}\text { Ordinary Course } \\
\text { of Business Ex- } \\
\text { ception }\end{array}$ & Medium & Low & AOL: Medium & AOL: High \\
\hline $\begin{array}{l}\text { Broad Protection } \\
\text { Approach }\end{array}$ & Low & Very High & AOL: Low & AOL: Medium \\
\hline $\begin{array}{l}\text { Direction of } \\
\text { Counsel } \\
\text { Approach }\end{array}$ & Medium & Medium & AOL: Medium & AOL: Very High \\
\hline $\begin{array}{l}\text { Denial } \\
\text { Presumption }\end{array}$ & Medium & Low & AOL: Low & AOL: Low \\
\hline $\begin{array}{l}\text { Ad Hoc Approach: } \\
\text { Primary Purpose } \\
\text { Formulation }\end{array}$ & Medium & Medium & AOL: High & AOL: Medium \\
\hline $\begin{array}{l}\text { Ad Hoc Approach: } \\
\text { Substantial } \\
\text { Prospect } \\
\text { Formulation }\end{array}$ & Low & High & BF: Low & BF: Low \\
\hline
\end{tabular}


While necessarily crude, this summary indicates that the denial presumption rule is the best approach. No strategy outperforms it in terms of administrative costs and side effects. While the broad protection and substantial prospect approaches have lower divergence costs than the denial presumption, each of these has substantially higher costs of other kinds. Thus, when all costs of each approach are aggregated and compared, the denial presumption approach comes out on top. ${ }^{82}$

In addition to suggesting the least costly interpretation of the work product doctrine, this analysis confirms the importance of considering the anticipation of litigation and bad faith issues simultaneously. As discussed above, if the denial presumption approach is used, the optimal rule holds that a plaintiff may not show substantial need based on a bare allegation of bad faith. ${ }^{83}$ Under such an approach, there is no difference between what is discoverable when a plaintiff includes a complaint of bad faith and when he does not. Consequently, courts will generally have few administrative costs beyond the original "anticipation of litigation" determination, and insurers will be able to predict with reasonable accuracy what sort of documents will have to be shared. Plaintiffs will have little to gain by including an allegation of bad faith, and thus will not file spurious claims.

At the same time, the possibility of an allegation of bad faith will discourage insurers from prematurely denying claims in an effort to shield their materials from discovery and frustrate the sharing rule. ${ }^{84}$ The possibility of complaints of bad faith may also decrease divergence costs resulting from discouraged pre-denial preparation, because insurers are less likely to underprepare if they fear their lack of preparation will come back to haunt them in the form of a complaint of bad faith. ${ }^{85}$ Moreover, the possibility of a complaint of bad faith is not an empty threat. Given that insureds already have access to a significant part of the file, they should have enough information to evaluate whether the insurer

Somewhat surprisingly, the ordinary course of business approach offers the next best solution. This outcome conflicts with the common view that the ordinary course of business exception does not really make sense in the insurance context, where many materials are prepared both in the ordinary course of business and in anticipation of litigation. See, for example, Wilson, Note, 1988 Colum Bus L Rev at 600 (cited in note 72); Stokes, 34 Baylor L Rev at 165 (cited in note 63). As discussed, this intellectual discomfort with the doctrine is reflected in the high general side effects. See Part IV.D. Apart from the side effects, however, the ordinary course of business exception performs well. In other words, while the test itself is somewhat unattractive, the resulting pattern of protection is quite tolerable in the insurance context.

${ }^{\infty}$ See Part IV.F.

${ }^{8}$ See Part IV.D.

${ }^{85}$ See Part IV.E. See also note 61 and accompanying text. 
acted in bad faith and to bring suit if warranted.$^{86}$ Hence, insurers will not be left unaccountable.

To maintain the advantages of the denial presumption approach best, courts should allow an insurer to overcome the presumption that a pre-denial document is subject to discovery only if the insurer can show that its primary purpose in preparing the document was for litigation. Further, courts should construe the primary purpose test to require a demonstration that the insurer did not use the document to make the claim decision. ${ }^{87} \mathrm{~A}$ strictly applied test will make it difficult for the insurer to win protection for pre-denial material, but at the same time, it will allow an insurer to protect materials clearly geared toward trial that just happened to be prepared before denial of the contested claim. ${ }^{88}$ Because the presumption would be difficult to overcome, insurers will rarely attempt to do so, limiting costs of judicial administration. Similarly, the insured could overcome the presumption that post-denial material is protected by demonstrating that the primary purpose of the material was not litigation. ${ }^{89}$

\section{CONCLUSION}

In formulating a sharing rule in insurance cases, courts should seek to encourage the optimal amount of trial preparation by insurers. To do so, judges must be sensitive to how insurers' incentives to prepare may diverge from society's desired level, and how the interpretation of the work product doctrine affects this divergence. Courts should be sensitive to the divergence costs, missed sharing costs, administrative costs, and side effects that accompany any interpretation of the work product doctrine.

Courts should realize that the "anticipation of litigation" requirement and the treatment of discovery requests in actions for bad faith are interdependent. A meaningful treatment of either issue requires consideration of the other. For cases involving first party insurance, the best strategy utilizes a presumption that an insurer's preparations are in anticipation of litigation only after a

\footnotetext{
${ }^{86}$ See Part IV.F.

${ }^{87}$ Such a test thus presumes that an insurer's primary purpose in preparing any predenial document useful to the claim decision was to assist in making the claim decision.

${ }^{8}$ This approach is slightly more generous than the Harper rule, which requires a demonstration that litigation was reasonably expected when the document was produced, and that the document was prepared and used solely for litigation. See text accompanying note $30 ; 138$ FRD at $663-64$.

${ }^{89}$ Overcoming the presumption in this direction is also quite difficult. Trying to demonstrate substantial need may be more fruitful for insureds than trying to overcome this presumption.
} 
claim is denied, along with a rule that an allegation of bad faith, without more, does not overcome work product protection. 


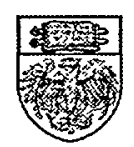

